\title{
Low quality of life scores in school children with attention deficit-hyperactivity disorder related to anxiety
}

\author{
Calidad de vida en niños escolares con transtorno por déficit de atención-hiperactividad \\ relacionada a niveles de ansiedad
}

Elizabeth Zambrano-Sánchez', José A. Martínez-Cortés², Yolanda del Río-Carlos ${ }^{3}$, Minerva Dehesa-Moreno³, Adrián Poblano ${ }^{4}$

\begin{abstract}
Objective: Attention deficit hyperactivity disorder (ADHD) is an alteration that begins early in infancy and whose cardinal symptoms are inattention, hyperactivity and impulsivity. There are few studies for specific tests to measure Quality of Life (QoL) in children with ADHD. Methods: We evaluated QoL of 120 children from 7-12 years of age with ADHD and of a group of 98 healthy control children. To measure QoL, we utilized the Questionnaire of Quality of Life for Children in Pictures (AutoQuestionnaire Qualite de Vie Enfant Imagé, AUQUEI). We evaluated anxiety in children by the Children's Manifest Anxiety Scale-Revisited (CMAS-R). We compared results among groups and employed the calculation of correlation between the AUQUEI questionnaire and the CMAS-R scale. Results: The total average of the AUQUEI questionnaire in children with ADHD was 45.2, while in the control group it was 54.3 ( $p<0.05)$. We also observed significant differences between the control group and groups of children with ADHD in the CMAS-R scale. We found significant correlations between AUQUEI questionnaire and CMAS-R scale. Conclusion: The main result was to the disclosure that low QoL scores in ADHD children was anxiety-related.
\end{abstract}

Key words: attention deficit disorder with hyperactivity, quality of life, anxiety.

\section{RESUMEN}

Objetivo: El trastorno por déficit de atención con hiperactividad (TDAH) es una alteración que comienza en la infancia y cuyos síntomas principales son la inatención, hiperactividad y la impulsividad. Hay pocos estudios que midan la Calidad de Vida (CV) en niños con TDAH. Métodos: Evaluamos la CV de 120 niños de 7-12 años de edad con TDAH y la de un grupo control de 98 niños. Para medir la CV, utilizamos el Cuestionario en figuras de la CV de niños (AutoQuestionnaire Qualité de Vie-Enfant-Imagé, AUQUEI). Evaluamos la ansiedad por medio de la Escala de Ansiedad Manifiesta en Niños - Revisada (Children's Manifest Anxiety Scale-Revisited, CMAS-R). Comparamos los resultados entre grupos y medimos la correlación entre AUQUEI y CMAS-R. El promedio total del AUQUEI en niños con TDAH fue 45,2, mientras que en el grupo control fue 54,3 (p<0.05). También observamos diferencias significativas entre el grupo control y los grupos de niños con TDAH en CMAS-R. Encontramos correlaciones significativas entre AUQUEI y CMAS-R. Conclusiones: Las calificaciones bajas de CV en niños con TDAH se relacionan a mayores niveles de ansiedad.

Palabras-Clave: trastorno por déficit de atención con hiperactividad, calidad de vida, ansiedad.

Attention deficit hyperactivity disorder (ADHD) is an alteration that begins early in infancy and whose cardinal symptoms are inattention, hyperactivity and impulsivity ${ }^{1}$. There are few studies on the validity and prognosis of early diagnosis of ADHD in preschool children despite early identification of the problem; it is very important to avoid negative complications ${ }^{2,3}$. Overall, children diagnosed with ADHD present several complications, such as oppositional-defiant disorder (ODD), conduct disorder (CD), learning disabilities (LD), depression and others ${ }^{4}$. Early identification and diagnosis of children with ADHD are very important to avoid complications and negative feelings from parents, teachers and

\footnotetext{
'B. Sc., Psychologist, Laboratory of Cognitive Neurophysiology, National Institute of Rehabilitation, Mexico City, Mexico;

${ }^{2} \mathrm{MD}$, Neurologist, Department of Neurological Rehabilitation, Mexico City, Mexico;

${ }^{3} \mathrm{MD}$, Psychiatrist, Department of Integral Rehabilitation, Mexico City, Mexico;

4MD, M. Sc., D. Sc., Neurophysiologist, Laboratory of Cognitive Neurophysiology, National Institute of Rehabilitation, Mexico City, Mexico.

Correspondence: Adrián Poblano; Calzada México-Xochimilco 289; Col. Arenal de Guadalupe Deleg. Tlalpan; 14389 Mexico City - Mexico; E-mail: drdyslexia@ latinmail.com

Conflict of interest: There is no conflict of interest to declare.
}

Received 14 July 2011; Received in final form 24 August 2011; Accepted 31 August 2011 
the children's peers at school', with the objective to achieving a better Quality of Life (QoL).

According to the World Health Organization (WHO), QoL is: "the individual's self-perception of his place in life in the cultural context and within a value system in which he lives in relation to its objectives, expectations, rules and wishes. It is a broad concept influenced in a complex manner by the physical health of the individual, his psychological status, independence level, social relationships, among other elements of his environment". Knowledge of QoL and its measurement must comprise a major point for diagnosis and treatment by the professionals caring for patients with $\mathrm{ADHD}$ and for improving the patient's expectations of life in the family, in school, at work and in society. There are many studies focused on the social, behavioral, emotional and academic environment of children with $\mathrm{ADHD}^{7,8}$. However, there are few papers describing how children with ADHD perceive themselves and self-evaluate their QoL in relation to anxiety. To know in detail the way in which ADHD alters the integral development of children and adolescents, it is necessary to investigate the life experiences of children with ADHD.

There are few studies for specific tests to measure QoL in children with $\mathrm{ADHD}^{9}$. In this paper, we utilized a QoL questionnaire for children with pictures (AUQUEI), which made it easy to identify and measure several components of QoL related with the behavior of children in school, at home and in other environments. To identify QoL, it is important to provide pathways into the children's families in a practical and rapid way and to foment the integration of patients into group intervention programs with the objective of addressing favorable lifestyle.

\section{METHODS}

\section{Subjects}

We evaluated children from 7-12 years of age that were students at a government-run-public elementary school who were referred as suspected of having ADHD by their school principal or teachers. The children were examined at the Laboratory of Cognitive Neurophysiology of the National Institute of Rehabilitation in Mexico City by means of neurological, psychiatric, neuropsychological, psychological and electrophysiological tests. In case of acceptance, they were included in the Prospective Study of Children of ADHD of Mexico City (PSC-ADHD-Mex) protocol. ADHD diagnosis was carried-out in agreement with recommendations of the American Psychiatry Association guidelines ${ }^{10}$, as published by our work team elsewhere in a three-step level evaluation. The first step was the at-school suspicion and screening; the second was conducted by means of the DSM-IV-R questionnaire; and the third comprised the semi-structured multidisciplinary interview, taking into account the persistence of the disorder for a period $>6$ months of ADHD symptoms in at least two environments, such as school and home ${ }^{2,11}$. Children with ADHD were classified into the three recognized DSM-IV-R subtypes, as follows: ADHD Combined (-C), mainly with Inattention symptoms (-I), and mainly with Hyperactivity-impulsivity (-H). All children with ADHD were medication-free and were questioned prior to examination concerning the consumption of any drugs. Exclusion criteria were the following: mental retardation, epilepsy, cerebral palsy, autism, blindness, deafness or another pediatric neurological behavioral condition. Moreover, exclusion criteria also included children who were previously tested within the last 6 months with the same neuropsychological or psychological tests that we employed in this research who were also rejected from participation in the study. We constructed a control group for comparison purposes of children from the same school with identical age and school grade with a similar socioeconomic background, but without diagnosis of ADHD. Parents and children of both groups were widely informed about the study and the importance of their participation in it. This investigation was approved by the Research and Ethics Committee of the National Institute of Rehabilitation, and informed consent was signed by the parents or guardians of participating children.

\section{Quality of Life Questionnaire}

To measure QoL in children with ADHD, we utilized the Questionnaire of Quality of Life for Children in Pictures (AutoQuestionnaire Qualité de Vie-Enfant-Imagé, AUQUEI) ${ }^{12,13}$, twice during follow-up, with a 6-months interval between tests. The AUQUEI is a specific questionnaire to measure a profile of satisfaction from the children's point of view; it was presented as pictures and was translated and standardized into the Spanish language. The questionnaire is addressed to children aged 4-12 years. The AUQUEI questionnaire was composed of 26 questions that explore familial and social activities, health, body functions and separation. Each item of the test is scored at 0, 1, 2 or 3 points, corresponding, respectively, to very unhappy, unhappy, happy and very happy conditions. The items are grouped into four factor dimensions of family and social life, leisure activities and health. Dimension order was as follows: F1 - family life and social relationships; F2 - leisure; F3 - separation; and F4 function performance. Each item can be answered by marking one of four options of pictures presented as children's faces with emotional state representing very unhappy, unhappy happy, and very happy emotional states.

\section{Children's Manifest Anxiety Scale}

We evaluated manifested anxiety in children by the Children's Manifest Anxiety Scale - Revisited (CMAS-R) ${ }^{14}$. The scale presented to the children was entitled "What I think and feel”, CMAS-R scale was constructed by 37 items. The scale was designed to measure the level and nature of anxiety in children and adolescents of 6 to 19 years of age. Total Anxiety Score is based on 28 items, which are in turn 
divided in three anxiety subscales: 1. Physiological anxiety; 2. Restless/Hypersensitivity; and 3. Social concerns/concentration. In addition, there are nine additional items that corresponded to a Lie subscale. Score of each scale was determined by the number of items answered with "yes".

Physiological anxiety subscale comprises 10 items. This scale is associated with body symptoms of anxiety, such as sleep disorders, nausea and fatigue. The Restless/ Hypersensitivity scale was composed of 11 items, and is associated with obsessive worries concerning several vaguely defined things in the mind of the child associated with the fear of being hurt or socially isolated. The Social concerns/concentration scale has seven items, and is particularly useful in identifying children with school difficulties and children occupied with thoughts of detractors and fears, the majority of them of a social or interpersonal nature that lead to difficulties in attention and concentration. Moreover, the CMAS-R scale has a 9-item in Lies subscale that is designed to detect social convenience, conformity and deliberate falsification of responses. Suspicion of lying invalidated all results from the remaining subscales of the CMAS-R scale.

\section{Statistics}

We measured the mean and standard deviation (SD) of continuous variables and percentages in binomial variables. We calculated internal reliability by Cronbach's alpha value for each 26 test-items for the AUQUEI questionnaire and the test-retest scores by means of the Spearman method. We used one-way Analysis of variance (ANOVA) to compare the means of three groups with the Tukey post-hoc test to locate differences among groups. We employed the calculation of correlation between the AUQUEI questionnaire and the CMAS-R scale by means of the Spearman method. The $a$-priori alpha value accepted was $\mathrm{p} \leq 0.05$. We utilized SPPS software version 14.0.

Table 1. Distribution of children in ADHD and the control group.

\begin{tabular}{lcc} 
Group & $\mathbf{n}$ & $\%$ \\
\hline ADHD-C & 67 & 56 \\
ADHD-I & 32 & 27 \\
ADHD-H & 21 & 17 \\
Controls & 86 & 100
\end{tabular}

ADHD-C: attention deficit hyperactivity disorder-Combined type; ADHD-I: attention deficit hyperactivity disorder-Inattentive type; ADHD-H: attention deficit hyperactivity disorder-hyperactive type.

\section{RESULTS}

We studied QoL scores measures in a group of 120 children with $\mathrm{ADHD}$ in an age range between 7 and 12 years; their results were compared with those deriving from a group of 98 healthy control children without ADHD. The group with ADHD had 87 male children (72\%) and 33 females $(27 \%)$, average age \pm standard deviation (SD) was 9.0 2.1 years (Table 1 ). The ADHD children's group had the following distribution: 67 children (56\%) had ADHD-C type, 32 children (26\%) had ADHD-H type, and 21 children (18\%) had ADHD-I type (Table 2). Moreover, we studied a group of 98 control children without ADHD from the same school and with identical socioeconomic background who served as a control population for comparison purposes. The control group was made up of 75 male children (77\%) and 23 female children (23\%), with an average age \pm SD of $9.4 \pm 2.3$ years (Table 1). There were no significant statistical differences in age among groups.

The total average of the AUQUEI questionnaire in children with $\mathrm{ADHD}$ was 45.2, while in the control group this was 54.3, which demonstrates significantly better value in QoL of control children when they are compared with the results of $\mathrm{ADDH}$ children group $(\mathrm{p}<0.05)$. The total average of the AUQUEI questionnaire score for each $\mathrm{ADHD}$ subtype was as follows: ADHD-C, 44.4; ADHD-I, 45.6; and ADHD-H, 45.7. Data of averages of each AUQUEI subtest in each ADHD type group are shown in Table 2. Cronbach's alpha measurement of the QoL questionnaire was $\alpha=0.86$. Test-Retest Spearman correlation coefficient of QoL questionnaires was determined at $r=0.84$. Measurement of the different subscales of the QoL questionnaire (life in family and society, leisure, separation and function performance) in each ADHD type showed significant differences between control children and children with $\mathrm{ADHD}$ in life in family and society subscales $(\mathrm{F}=3.2, \mathrm{df}=3,57, \mathrm{p}=0.05)$, and function performance subscale $(\mathrm{F}=4.6, \mathrm{df}=3,57, \mathrm{p}=0.01)$. Tukey post-hoc analysis showed that differences were localized between ADHD-H and ADHD-I with respect to the control group, and between ADHD-I and the control group, respectively (Table 2).

We observed significant differences between the control group and groups of children with ADHD-I, ADHD-H and ADHD-C in the CMAS-R scale. In each subscale, significant

Table 2. AUQUEI questionnaire scores by subtest in the different groups of ADHD and the control group.

\begin{tabular}{|c|c|c|c|c|c|c|c|c|c|c|}
\hline \multirow{2}{*}{ Subscale } & \multicolumn{2}{|c|}{ Control } & \multicolumn{2}{|c|}{ ADHD-C } & \multicolumn{2}{|c|}{ ADHD-H } & \multicolumn{2}{|c|}{ ADHD-I } & \multirow{2}{*}{$\mathrm{F}$} & \multirow{2}{*}{$p$-value } \\
\hline & $x$ & SD & $x$ & SD & $x$ & SD & $x$ & SD & & \\
\hline Family life and social relationships & 9.1 & 2.4 & 7.6 & 2.3 & 6.7 & 3.8 & 6.7 & 3.2 & 3.2 & $0.05^{*}$ \\
\hline Leisure & 15.3 & 2.0 & 14.2 & 2.2 & 13.1 & 4.6 & 14.3 & 2.1 & 1.5 & 0.21 \\
\hline Separation & 4.0 & 1.8 & 4.2 & 2.0 & 3.0 & 2.3 & 3.3 & 1.8 & 0.84 & 0.47 \\
\hline Functions performance & 11.05 & 2.9 & 9.4 & 2.9 & 10.2 & 3.4 & 8.6 & 2.5 & 4.6 & $0.01 *$ \\
\hline
\end{tabular}

*Statistically significant. AUQUEI: questionnaire of quality of life for children in pictures; ADHD: attention deficit hyperactivity disorder; C: combined type; I: inattentive type; H: hyperactive type; SD: standard deviation. 
Table 3. CMAS-R scale scores by subtest in the different groups of ADHD and the control group.

\begin{tabular}{|c|c|c|c|c|c|c|c|c|c|c|}
\hline \multirow{2}{*}{ Subscale } & \multicolumn{2}{|c|}{ Control } & \multicolumn{2}{|c|}{ ADHD-C } & \multicolumn{2}{|c|}{ ADHD-H } & \multicolumn{2}{|c|}{ ADHD-I } & \multirow{2}{*}{$\mathrm{F}$} & \multirow{2}{*}{$\mathrm{p}$-value } \\
\hline & $\mathrm{x}$ & SD & $x$ & SD & $x$ & SD & $x$ & SD & & \\
\hline Physiological anxiety & 7.3 & 2.6 & 13.7 & 1.3 & 13.4 & 1.6 & 13.7 & 1.3 & 6.1 & $0.01 *$ \\
\hline Restless/hypersensitivity & 5.9 & 0.9 & 13.5 & 1.5 & 12.7 & 1.04 & 13.5 & 1.5 & 7.6 & $0.01 *$ \\
\hline Social concern/concentration & 6.0 & 0.9 & 12.4 & 1.7 & 12.2 & 1.7 & 12.4 & 1.7 & 6.4 & $0.01 *$ \\
\hline Lies & 7.6 & 1.6 & 8.6 & 1.7 & 8.6 & 1.7 & 8.6 & 2.8 & 2.0 & 0.15 \\
\hline
\end{tabular}

*Statistically significant. CMAS-R: children's manifest anxiety scale-revisited; ADHD: attention deficit-hiperactivity disorder; C: combined type; I: inattentive type; $\mathrm{H}$ : hyperactive type; SD: standard deviation.

Table 4. Significant correlations between AUQUEI questionnaire and CMAS-R scale in children with ADHD.

\begin{tabular}{lcc} 
CMAS-R test & \multicolumn{2}{c}{ AUQUEI test } \\
Family life and & $\begin{array}{c}\text { Functions } \\
\text { social relationships }\end{array}$ & $r=0.61$ \\
\hline $\begin{array}{l}\text { Restless/ } \\
\text { hypersensitivity }\end{array}$ & $r=0.63$ & $r=0.58$ \\
$\begin{array}{l}\text { Social concern/ } \\
\text { concentration }\end{array}$ & $r=0.52$ & $r$
\end{tabular}

AUQUEl: questionnaire of quality of life for children in pictures; CMAS-R: children's manifest anxiety scale-revisited; ADHD: attention deficit hiperactivity disorder.

differences were found as follows: in the Physiological anxiety scale $(\mathrm{F}=6.10 ; \mathrm{df}=2,203 ; \mathrm{p}=0.01)$, Restless/Hypersensitivity $(\mathrm{F}=7.60 ; \mathrm{df}=2,203 ; \mathrm{p}=0.01)$ and Social concerns/concentration $(\mathrm{F}=6.40 ; \mathrm{df}=2,203 ; \mathrm{p}=0.01$ ) (Table 3 ). Tukey post -hoc analysis showed that differences were localized between the control group with respect to ADHD-I, ADHD-H and ADHD-C groups (Table 3). We found no significant differences in the Lies subscale between the control group and the groups of children with ADHD.

We found significant correlations between family life and social relationships subscale (AUQUEI questionnaire) and restless/hypersensitivity (CMAS-R scale); performance functions (AUQUEI questionnaire) and restless/hypersensitivity (CMAS-R scale), family life and social relationships domain (AUQUEI questionnaire) and social concerns/concentration (CMAS-R scale); and between performance functions (AUQUEI questionnaire) and social concerns/concentration (CMAS-R scale) (Table 4).

\section{DISCUSSION}

The main result from this investigation was the disclosure that low QoL scores in ADHD children revealed data form the own children's self-reports and, as predicted in the hypothesis, was anxiety-related. On the other hand, as expected from the results from many studies in the medical literature, we confirmed that children with ADHD showed lower QoL scores when compared with healthy control children without $\mathrm{ADHD}^{15}$.

Lower QoL of children with ADHD has been known for some time, as noted previously ${ }^{16}$; however, the causes of this fact remain unrevealed. The relationship between QoL and anxiety in children with ADHD has been scarcely studied.
Thus, this study proposal was that low QoL in children with ADHD was related to higher levels of anxiety.

In one research, 929 young draftees in the Taiwanese Army completed the Adult ADHD Self-Report Scale (ASRS), the WHO Quality of Life-Brief Version, the Epworth Sleepiness Scale, the second edition of the Beck Depression Inventory and the Beck Anxiety Scale. Based on high ASRS scores, a total of 328 adults (35.3\%) were identified as having ADHD: 65 (7.0\%) with definite ADHD and 263 (28.3\%) with probable ADHD. The subjects in the ADHD group had more severe depressive, anxiety symptoms and daytime sleepiness, and had poorer QoL than the 601 controls. The authors concluded that ADHD should be included in the differential diagnosis for young males presenting with anxiety, depression, daytime sleepiness, and poor $\mathrm{QoL}^{17}$. Comparison among studies is difficult because of differences in the tests applied to study QoL and anxiety, and in age at time of study, but, overall, these data are in agreement with our results in showing a close relationship between poor QoL related with anxiety and depression.

Recently other researchers investigated changes that occur in depression, anxiety, obsessive-compulsive symptoms and health-related QoL during methylphenidate (MPH) treatment in children with ADHD. Forty-five treatment naive children with ADHD, aged 8-14 years, were assessed based on self, parent and teacher reports at baseline and at the end of the first and third month of MPH treatment regarding changes in inattention, hyperactivity, impulsivity, depression, anxiety and obsessive-compulsive symptoms. Changes in QoL were also investigated. Symptoms of inattention, hyperactivity and impulsivity were significantly reduced following a 3-month MPH treatment. There were significant decreases in depression, trait anxiety and checking compulsion symptom scores. Moreover, parents reported significant improvements in psychosocial and total QoL score, despite no change in physical health scores. Children's ratings of QoL measurements showed no significant changes in physical health and psychosocial scores, while total scores significantly improved after treatment. The researchers concluded that, over a 3-month MPH treatment, depression, trait anxiety and checking compulsion symptoms decreased and that QoL improved, along with the symptoms of inattention, hyperactivity and impulsivity ${ }^{18}$.

We speculated that several symptoms of ADHD, such as alterations of executive functions ${ }^{19}$, may alter decision-marking; thus, children with ADHD can make incorrect choices 
that alter their relations with their peers, parents and school authorities that result in increased anxiety. This hypothesis is additional investigation and will be the subject of other future researches by our work team.

Our data were in agreement with several investigations. QoL describes an individual's subjective perception of their position in life as evidenced by their physical, psychological and social functioning. QoL has become an increasingly important outcome measurement in child mental health clinical work and research. Here, we provide data on QoL in children with ADHD and address two main questions. 1. What is the impact of QoL in children with ADHD? and 2. What are the relationships among ADHD anxiety symptoms, functional impairment and QoL mediators and moderators in ADHD? Relevant articles had identified robust negative effects on QoL reported by the parents of children with ADHD across a broad range of psychosocial, achievement and self-evaluation domains ${ }^{20}$. Children with ADHD rate their own QoL less negatively than their parents do, and do not always observe themselves as functioning less well than healthy controls. ADHD has a comparable overall impact on QoL compared with other mental health conditions and severe physical disorders ${ }^{21,22}$, increased symptom level and impairment predicts poorer $\mathrm{QoL}^{23}$. The presence of comorbid conditions or psychosocial stressors aids explains these effects.

There is emerging evidence that QoL improves with effective treatment ${ }^{24}$. Thus, ADHD seriously compromises QoL, especially when observed from parents' perspective. QoL outcomes should be included as a matter of course in future treatment studies. Finally, we recognize that our study has several limitations. It is necessary to study a larger population to obtain stronger conclusions. Thus, additional research is necessary to overcome and to reinforce our results for the use of a QoL instrument in the study of children with ADHD in clinical practice.

\section{References}

1. Keiling $\mathrm{C}$, Keiling RR, Rohde LA, et al. The age at onset of attention deficit hyperactivity disorder. Am J Psychiatry 2010;167:14-16.

2. Poblano A, Romero E.ECl-4 screening of attention deficit-hyperactivity disorder and co-morbidity in Mexican preschool children: preliminary results. Arq Neuropsiquiatr 2006;64:932-936.

3. Galéra C, Melchior M, Chastang JF, Bouvard MP, Fombonne E. Childhood and adolescent hyperactivity-inattention symptoms and academic achievement 8 years later: The GAZEL youth study. Psychol Med 2009;39:1895-1906.

4. Gau SS, Ni HC, Shang CY, et al. Psychiatric comorbidity among children and adolescents with and without persistent attention-deficit hyperactivity disorder. Aust NZJ Psychiatry 2010;44:135-143.

5. Paulson JF, Buermeyer JC, Nelson-Gray RO. Social rejection and ADHD in young adults: an analogue experiment. J Atten Disord 2005;8:127-135.

6. Eriksson M, Lindström B. A salutogenic interpretation of the Ottawa Charter. Health Promot Int 2008;23:190-199.

7. Flicek M. Social status of boys with both academic problems and attention-deficit hyperactivity disorder. J Abnorm Child Psychol 1992;20:353-366.

8. Pongwilairat K, Louthrenoo O, Charnsil C, Witoonchart C. Quality of life of children with attention-deficit/hyperactivity disorder. J Med Assoc Thai 2005;88:1062-1066.

9. Topolski TD, Edwards TC, Patrick DL, Varley P, Way ME, Buesching DP. Quality of life of adolescent males with attention-deficit hyperactivity disorder. J Atten Disord 2004;7:163-173.

10. American Psychiatric Association. Diagnostic and Statistical Manual of Mental Disorders. $4^{\text {th }}$ edition (DSM-IV). Washington: American Psychiatric Association; 1994.

11. Zambrano-SánchezE, Martínez-Cortés JA, Del Río-Carlos Y, MartínezWbaldo MC, Poblano A. Identification of attention deficit-hyperactivity disorder and conduct disorder in Mexican children by the scale of evaluation of deficit of attention and hyperactive. Psychiatry Res 2010;187:437-440.

12. Manificat S, Dazord A. Assessment of quality of life in pediatrics: a questionnaire to assess the child's own opinion. Neuropsychiatr Enfance Adolesc 1997;45:106-114.

13. Manificat S, Dazord A. Children's quality of life assessment: preliminary results obtained with the AUQUEI questionnaire. Qual Life Newslett 1998;19:2-3
14. Reynolds CR, Richmond BO. Children Manifested Anxiety ScaleRevisited (in Spanish). Mexico City: Manual Moderno; 2005.

15. Danckaerts M, Sonuga-Barke EJ, Banaschewski T, et al. The quality of life of children with attention deficit/hyperactivity disorder: a systematic review. Eur Child Adoles Psychiatry 2010;19:83-105.

16. Wehmeier PM, Schacht A, Barkley RA. Social and emotional impairment in children and adolescents with ADHD and the impact on quality of life. J Adolesc Health 2010;46: 209-217.

17. Chao CY, Gau SS, Mao WC, Shyu JF, Chen YC, Yeh CB. Relationship of attention-deficit-hyperactivity disorders symptoms, depressive/ anxiety symptoms, and life quality young men. Psychiatry Clin Neurosc 2008;62:421-426.

18. Gürkan K, Bilgic A, Türkoglu S, Kilic BC, Aysev A, Uslu R. Depression, anxiety and obsessive-compulsive symptoms and quality of life in children with attention-deficit hyperactivity disorder (ADHD) during three-months methylphenidate treatment. J Psychopharmacol 2010;24:1810-1818.

19. Zambrano-Sánchez E, Martínez-Cortés JA, del Río-Carlos Y, Martínez-Wbaldo MC, Poblano A. Executive dysfunction screening and intellectual coefficient measurement in children with attention deficit-hyperactivity disorder. Arq Neuropsiquiatr 2010;68:545-549.

20. Riley AW, Coghill D, Forrest CB, et al. Validity of the health-related quality of life assessment in the ADORE study: Parent Report Form of the CHIP-Child Edition. Eur Child Adolesc Psychiatry 2006;15 (Suppl 1):S163-S171.

21. Cohen $\mathrm{Cl}$, Hassamal SK, Begum M. General coping strategies and their impact on quality of life in older adults with schizophrenia. Schizophr Res 2011;127:223-228.

22. Sandella DE, O’Brien ML, Shank LK, Warschausky SA. Sleep and quality of life in children with cerebral palsy. Sleep Med 2011;12: 252-256.

23. Wilens T, Biederman J, Brown S. Psychiatric comorbidity and functioning in clinically referred preschool children and schoolage youths with ADHD. J Am Acad Child Adolesc Psychiatry 2002; 41:262-268.

24. Perwien AR, Faries DE, Kratochvil CJ, Sumner CR, Kelsey DK, Allen AJ. Improvement in health-related quality of life in children with ADHD: an analysis of placebo controlled studies of atomoxetine. J Dev Behav Pediatr 2004;25:264-271. 